\title{
ROTEIRIZAÇÃO TURÍSTICA COMO INSTRUMENTO DE DESENVOLVIMENTO TERRITORIAL: \\ O ROTEIRO 'VERDE QUE TE QUERO VERDE' DE CAMPO MAGRO/PARANÁ (BRASIL)
}

Clotilde Zai ${ }^{1}$

CiCILIAN LUIZA LÖWEN SAHR ${ }^{2}$

\begin{abstract}
RESUMO - O turismo vem contribuindo para o desenvolvimento do entorno rural do Aglomerado Urbano de Curitiba, região de grande concentração urbana localizada no leste do estado do Paraná. Roteiros turísticos rurais são os instrumentos utilizados para o fomento desse desenvolvimento. Objetiva-se aqui analisar a articulação entre roteirização turística e desenvolvimento territorial a partir da constituição de sistemas de autogovernança: as associações de roteiros. O aprofundamento empírico se volta ao roteiro 'Verde Que te Quero Verde', que se localiza no município de Campo Magro. A abordagem utilizada é qualitativa e se pauta em entrevistas de profundidade e observação in loco. Avalia-se o processo de gestão do roteiro, as relações entre o roteiro e o Aglomerado Urbano de Curitiba, bem como, os impactos positivos e negativos gerados pela atividade turística. A autonomia dos empreendedores locais na gestão do roteiro, conjugada ao intenso fluxo de turistas e visitantes, trouxe nova dinâmica a zona rural de Campo Magro garantindo, além da permanência dos moradores na zona rural, melhoria nas condições e qualidade de vida desses. Portanto, pode-se concluir que a roteirização estudada constituiu-se num exemplo de sucesso de desenvolvimento territorial.
\end{abstract}

Palavras-chave: Roteirização turística; desenvolvimento territorial; Campo Magro; Paraná; Brasil.

ABSTRACT - TOURISTIC ROUTE AS A TOOL FOR TERRITORIAL DEVELOPMENT: THE 'VERDE QUE TE QUERO VERDE' ROUTE IN CAMPO MAGRO/PARANÁ (BRASIL). Tourism has contributed to develop the rural surroundings of the Curitiba urban

Recebido: dezembro 2017. Aceite: março 2019.

1 Doutoranda do Programa de Pós-Graduação em Geografia da Universidade Federal do Paraná, Rua Cel. Francisco H. dos Santos S/N, 81530-000, Centro Politécnico, Curitiba - Paraná, Brasil. E-mail: clotildezai@yahoo.com.br

2 Professora dos Programas de Pós-Graduação em Geografia da Universidade Federal do Paraná e da Universidade Estadual de Ponta Grossa, Ponta Grossa, Brasil. E-mail: cicilian@uol.com.br 
nucleus, a region of great urban concentration which is localized in the East of the Paraná State, Brazil. Touristic Routes are the tools to foment such a development. In this context, the articulation between touristic route planning and territorial development will be analyzed from a perspective of self-constituted systems of self-government, the route associations. Empirical evidence will be drawn from the 'Verde Que te Quero Verde' Route in the Campo Magro Municipality (Paraná, Brazil). The approach is qualitative and based on indepth interviews and local observations. Thus, the investigation refers to the natural and cultural potential, the transformations that have affected the local productive system, the process of route planning, the relations between the route and the Urban Nucleus of Curitiba, as well as the positive and negative impact of tourism activities. The autonomy of local entrepreneurs to manage the route, together with an intense movement of tourists and visitors, has brought a new dynamic to the rural zone of Campo Magro, thus guaranteeing better quality and living conditions for the population that also has persisted in its rural area. Therefore, it can be concluded that the route in study can be evaluated as a successful example of territorial development.

Keywords: Touristic route planning; territorial development; Campo Magro; Paraná; Brazil.

RÉSUMÉ - ITINÉRAIRE TOURISTIQUE COMME INSTRUMENT DE DÉVELOPPEMENT TERRITORIAL: LE GUIDE TOURISTIQUE 'VERDE QUE TE QUERO VERDE' DE CAMPO MAGRO/PARANÁ (BRÉSIL). Le tourisme contribue au dévoloppement de la zone rurale que se localise aux alentours de l'Agglomération Urbaine de Curitiba, une région de grande concentration urbaine située à l'est de l'État du Paraná. Les itinéraires touristiques ruraux sont des instrumentss utilisés pour la promotion de ce développement. L'objectif de ce travail est d'analyser l'articulation entre la création d'itinéraires touristiques et le développment territorial a partir de la construction de système d'autogouvernance: les associations de guides (parcours) touristiques. Létude empirique qui a été réalisée se base sur le guide touristique 'Verde Que te Quero Verde', que se localise dans la municipalité de Campo Magro. Lapproche de travail adoptée est qualitative et se base sur l'application d'interviews approfondies et observation in loco. Il y est évalué le processus de gestion de l'itinéraire, les relations entre l'itinéraire et l'Agglomération Urbaine de Curitiba, de même que les impacts positifs e négatifs engendrés par l'activité touristique. Lautonomie des entrepreneurs locaux dans le processus de gestion de l'itinéraire, combinée à l'intense flux de touristes et de visiteurs, a entrainé une nouvelle dynamique à la zone rurale de Campo Magro garantissant, en plus de la permanence de la population rurale, une amélioration de leurs conditions et qualité de vie. Donc, on peut conclure que l'itinéraire touristique qui a été étudié s'est constitué comme un exemple réussi de développement territorial.

Mots-clés: Itinéraire touristique; développement territorial; Campo Magro; Paraná; Brésil.

RESUMEN - RUTA TURÍSTICA COMO INSTRUMENTO DE DESARROLLO TERRITORIAL: LA RUTA DE 'VERDE QUE TE QUERO VERDE' DE CAMPO MAGRO/ PARANÁ (BRASIL). El Turismo ha contribuido al desarrollo del entorno rural del Aglomerado Urbano de Curitiba, región de gran concentración urbana localizada al este del estado de Paraná. Las rutas turísticas son los instrumentos utilizados para el fomento de este desarrollo. En este contexto, se analiza la articulación entre la creación de rutas turísticas y el 
desarrollo territorial a partir de la constitución de sistemas de auto-gobernanza: las asociaciones de rutas turísticas. El estudio empírico se centra en la ruta 'Verde Que te Quero Verde', localizada en el municipio de Campo Magro. El abordaje utilizado es cualitativo y se basa en entrevista a profundidad y observación in loco. Se evalúa el potencial natural y cultural explorado, las transformaciones ocurridas en el sistema productivo local, el proceso de gestión de la ruta, las relaciones entre la ruta y el Aglomerado Urbano de Curitiba, así como, los impactos positivos y negativos generados por la actividad turística. La ruta, que tiene a Curitiba como principal público consumidor, se presenta como un ejemplo de éxito en términos de desarrollo territorial rural. El mismo, explora los potenciales de la producción agroecológica, las fiestas típicas, la gastronomía, la naturaleza y la arquitectura, agregando valor a los productos y propiedades rurales por medio de asociaciones y cualificación de los emprendedores.

Palabras claves: Ruta turística; desarrollo territorial; Campo Magro; Paraná; Brasil.

\section{INTRODUÇÃO}

Nos últimos anos o conceito 'desenvolvimento territorial' vem ganhando destaque tanto no debate científico como nas políticas públicas. A influência das discussões e experiências de outros países marca a atuação do Estado brasileiro e de atores locais na promoção deste desenvolvimento. Neste contexto, a roteirização turística vem se tornando um dos instrumentos para operacionalização dessa abordagem.

Partindo deste pressuposto, o objetivo central desta investigação é analisar a articulação entre roteirização turística e desenvolvimento territorial a partir da constituição de sistemas de autogovernança - as associações de roteiros - no entorno rural do Aglomerado Urbano de Curitibai região localizada no Leste do Paraná. A intenção é: a) avaliar o processo de gestão ou "governança" dos roteiros de turismo; b) captar as relações do roteiro de turismo rural com o Aglomerado Urbano de Curitiba; c) verificar os impactos gerados pelos roteiros.

O roteiro 'Verde Que te Quero Verde', escolhido para dar profundidade à análise, está localizado na área rural do município de Campo Magro (fig.1), ou seja, no entorno do Aglomerado Urbano de Curitiba. Ele teve sua primeira organização em 1997 a partir de uma iniciativa dos empreendedores juntamente com a Prefeitura Municipal de Campo Magro e do Serviço Brasileiro de Apoio às Micro e Pequenas Empresa (Sebrae). Atualmente este é administrado pela Associação de Turismo de Campo Magro (ATCM).

$\mathrm{O}$ artigo estrutura-se em três seções. Inicia com uma discussão teórica sobre roteirização turística e desenvolvimento territorial, procurando articular os conceitos e direcionar as reflexões para o rural. Prossegue com a apresentação do roteiro 'Verde Que te Quero Verde', selecionado para este estudo de caso, bem como, das técnicas de pesquisa empregadas. Finaliza com a apresentação e discussão dos resultados alcançados, avaliando este roteiro turístico enquanto instrumento de desenvolvimento territorial. 


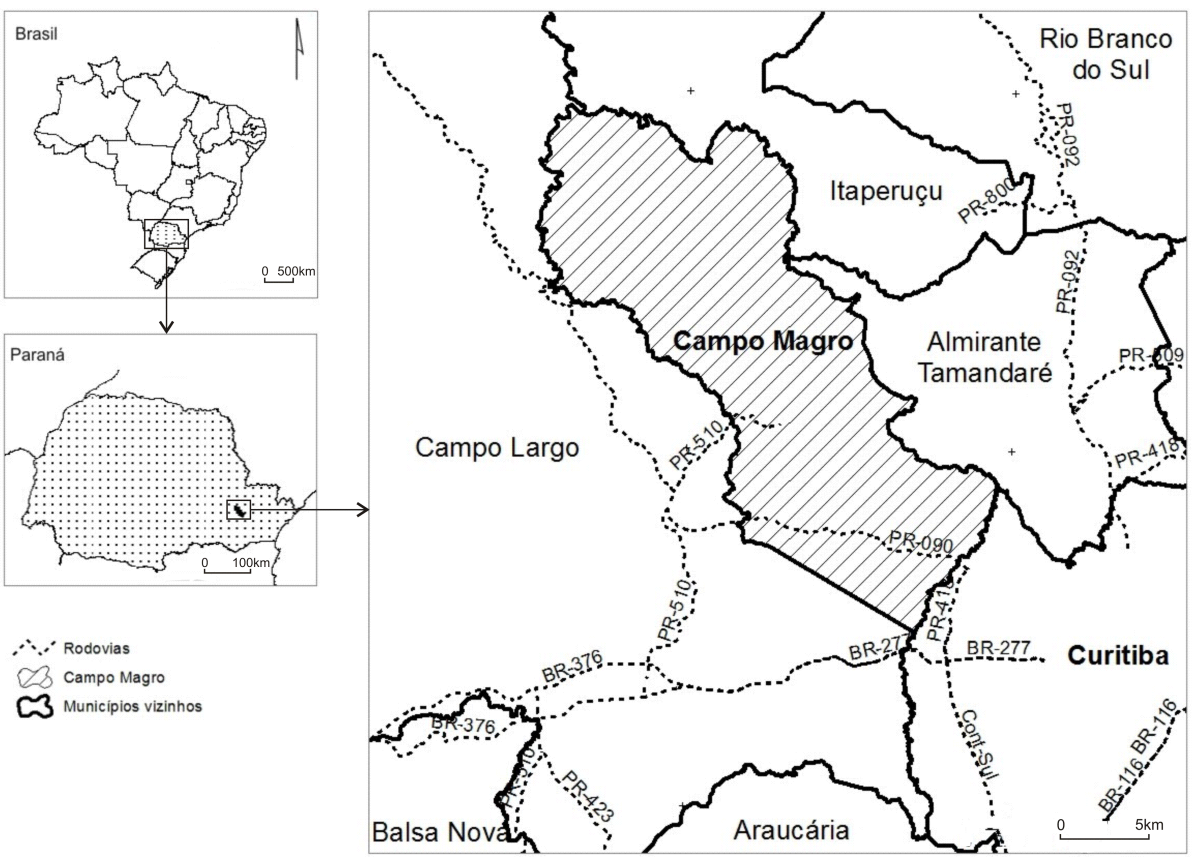

Fig. 1 - Localização do Município de Campo Magro no Paraná e no Brasil.

Fig. 1 - Localization of the Municipality of Campo Magro, Paraná, Brazil.

\section{ROTEIRIZAÇÃO TURÍSTICA E DESENVOLVIMENTO TERRITORIAL: ARTICULANDO CONCEITOS}

Roteiros de turismo têm-se multiplicado por todo mundo nas últimas duas décadas, não apenas em países desenvolvidos. Eles oferecem importantes oportunidades de dispersão e desenvolvimento de produtos e, ao mesmo tempo, de visitação por turistas que primam por experimentar novidades. Meyer (2004) defende a ideia de que a roteirização é uma oportunidade para regiões menos maduras em termos de inserção econômica, mas que apresentam recursos naturais e culturais com potencial para agradar turistas, que passam a prolongar seus interesses particulares. Assim, ao contrário de produtos turísticos segmentados, voltados exclusivamente a visitantes de longo tempo (como resorts por exemplo), os roteiros podem apelar a uma grande variedade de usuários.

$\mathrm{O}$ traçado de percursos orientados à atividade turística tende a valorizar o território e seus atrativos. Segundo Figueira (2013, p. 122), eles "implicam modificações e intrusões nas paisagens, quer pela reconversão de caminhos antigos em rotas turísticas, quer quando desenhados a propósito". Os atrativos constituem-se, portanto, em "espaços dispostos lateralmente ao eixo definido de cada percurso" (2013, p. 122) e possuem relevância na eficácia dos circuitos, pois se tornam alternativas de entretenimento para os visitantes. 
A roteirização turística, todavia, não é vista da mesma forma entre os autores. Brambatti (2002, p. 15) aborda roteirização como "percursos, caminhos, rotas percorridas por turistas, com o objetivo de usufruir de um contexto, visto no seu conjunto, de forma organizada e atrativa”. Já Moletta (2002) entende o roteiro turístico como um pequeno plano de viagem em que o turista segue a descrição de todos os pontos a serem visitados, tendo estipulado o tempo de permanência em cada local e a noção dos horários de parada. Nestes dois conceitos a análise parte da perspectiva do turista, sendo entendido como um ganho a este por oferecer um conjunto de atrativos organizados em um contexto.

Congregando diferentes aspectos, todavia ainda restringindo-se a perspectiva do turista, Scherer (2014) aponta que a organização dos atrativos em roteiros promove o consumo do produto turístico por meio dos elos entre diferentes atrativos. Para a autora, isso permite uma visão mais abrangente de um espaço "físico ou histórico, harmonizando um ambiente favorável que possibilita ao turista o contato e conhecimento de um maior número de locais e uma melhor visão socioeconômica e cultural" (Scherer, 2014, p. 54).

Para Tavares (2002, p. 15), "os roteiros turísticos são uma das principais maneiras de contextualizar os atrativos ativos de uma localidade" e, logo, de "potencializar seu poder de atratividade". Neste conceito, embora similar ao de Brambatti (2002), a análise parte da perspectiva do empreendedor e/ou do conjunto de empreendedores, apontando a roteirização como estratégia coletiva para ampliação de atratividade de seus empreendimentos individuais.

Há, portanto, autores que focam a análise nos roteiros turísticos enquanto estratégia de marketing regional. Para Meyer (2004, p. 20), "as rotas são usadas para transmitir uma imagem unificada de uma região em termos de um tema". Dessa maneira, supõe-se, em muitos casos, que não só a rota em si seja temática, mas que sua infraestrutura de serviços e equipamentos também carregue elementos dessa. Para a autora, a criação de uma imagem é crucial para atrair o interesse de potenciais visitantes, principalmente num ambiente competitivo. Também Cooper, Hall, e Trigo (2011, p. 21) defendem que a "imagem é decisiva para qualquer destino turístico" e, principalmente, para sua comercialização.

Brambatti (2002, p. 16), já citado anteriormente, aprofunda a análise salientando que "o roteiro surge como algo próprio do lugar. Algo que só acontece ali e que faz a vantagem comparativa frente aos outros produtos e atrações". Ainda nesta abordagem, Bahl (2004) enfatiza que os roteiros precisam ser organizados sublimando as potencialidades e as particularidades locais, bem como, tendo em vista sua demanda. Desta forma, a análise da roteirização turística toma outra perspectiva, a do potencial endógeno.

Bahl (2004) vai além, apontando também a perspectiva do planejamento do turismo. Ele ressalta a necessidade de se planejar e/ou controlar os elementos intervenientes, que se referem: a) às condições logísticas utilizadas pelo turista e sua adequação ao local; b) a qualidade e número de atrativos que serão visitados; c) aos serviços de hospedagem e restauração que serão ofertados; e d) ao tempo desprendido no roteiro, que necessita de uma sincronização entre seus elementos. 
Também as reflexões de Meyer (2004) caminham nesta direção, entretanto, já apontando elementos territoriais. A autora defende que para a roteirização alcançar seus objetivos, são necessários os seguintes ingredientes: a) redes de cooperação, pensamento regional e liderança; b) desenvolvimento de produtos, infraestrutura e acesso; c) participação da comunidade, desenvolvimento de microempresas e inovação; d) informação e promoção; e e) foco social explícito. Essa tendência, que valoriza a dimensão espacial da economia, bem como, as iniciativas locais de desenvolvimento, traz à tona a discussão de desenvolvimento territorial (Veiga, 2002).

Silva (2006) apresenta a dimensão territorial no planejamento turístico comparando dois modelos. Para o autor, o modelo do polo de crescimento, que inspira os "polos turísticos", privilegia os aspectos atrelados à função de especialização regional, ou seja, o turismo em si. Sua prática acontece ligada a investimentos exógenos que não empregam, numa escala otimizada, recursos produtivos de base local. Já o modelo territorialista e endógeno recomenda a prevalência do território sobre a função, sendo considerado, portanto, mais adequado ao planejamento do desenvolvimento turístico por propiciar um efetivo grau de endogeneização dos benefícios socioeconômicos gerados no processo.

Neste contexto, a abordagem territorialista e endógena apresenta-se como mais apropriada, sobretudo quando a roteirização turística visa o que Souza (2013, p. 275) enfatiza como desenvolvimento socioespacial, ou seja, "um processo de enfrentamento da heteronomia [poder de cima para baixo] e tendo a autonomia como um horizonte de pensamento e ação" (grifo do autor). Souza associa o desenvolvimento à ideia de autonomia, seja individual ou coletiva. Assim, traz à tona a necessidade de se discutir governança enquanto instrumento de desenvolvimento.

O território deve, portanto, prevalecer sobre a função turística que se pretende incorporar quando da implantação de roteiros. Dessa maneira, compreende-se que o turismo deva exercer um papel articulador e indutor de desenvolvimento, atuando de forma agregada e integrada com as demais atividades econômicas e socioculturais já existentes, bem como, com as características físicas e naturais que se apresentam. Entende-se, assim, que a roteirização turística em si não seja necessariamente responsável pelo desenvolvimento, entretanto, esta pode se constituir em um importante instrumento para persegui-lo.

\section{O ROTEIRO ‘VERDE QUE TE QUERO VERDE’ COMO ESTUDO DE CASO E A CONSTRUÇÃO METODOLÓGICA DA PESQUISA}

Para a operacionalização da investigação e aproximação para com a realidade, utilizou-se uma abordagem qualitativa. A escolha de um caso para aprofundamento do estudo deu-se dentre os roteiros rurais do entorno do Aglomerado Urbano de Curitiba que possuem sistema de autogovernança, ou seja, que seguem um ideal autonomista.

Atualmente têm-se oito roteiros de turismo rural com associação estruturada nesta área delimitada. $\mathrm{O}$ município de Colombo conta com o 'Circuito italiano de turismo rural', Campo Magro tem o roteiro 'Verde Que te Quero Verde', Almirante Tamandaré o 
'Circuito da natureza', São José dos Pinhais possui o 'Caminho do vinho', 'Caminho das colônias' e 'Circuito rural Taquaral', Araucária possui o roteiro polonês 'Caminhos de Guajuvira', Campo Largo tem o "Turismo rural nas colônias polonesas”ii.

O roteiro escolhido para aprofundamento da análise foi o 'Verde Que te Quero Verde' de Campo Magro, o qual apresenta um foco (agro)ecológico. Tal escolha se justifica por ser esse um exemplo de criação de imagem turística a partir de características endógenas, aspecto fundamental para o desenvolvimento territorial. Ele carrega a temática ecológica e incorpora dentro deste tema elementos da cultura italiana e polonesa dispostos na paisagem, embaranhando a arquitetura, a religiosidade, os atrativos e a gastronomia. Mesmo nos serviços de eventos e hospedagem há o esforço para que venham a fazer parte da imagem turística criada.

Na sequência, faz-se uma caracterização do roteiro com enfase nos atrativos e eventos que oferece, bem como, uma apresentação da construção metodológica da pesquisa. Esta se estruturou, sobretudo, a partir de entrevistas em profundidade, bem como, técnicas de observação in loco, realizada através de imersão na área em estudo.

\section{Caracterização do roteiro}

O 'Verde Que te Quero Verde' (fig. 2) está localizado na área rural do município de Campo Magro. Grande parte de seu relevo é bastante declivoso, estando numa área com rico potencial natural. Abriga dois significativos mananciais para abastecimento público de água, sendo o manancial subterrâneo do Carste e o manancial superficial dos rios Passaúna e Verde. Possui duas unidades de conservação, a Área de Proteção Ambiental do Passaúna e a Unidade Territorial de Planejamento de Campo Magro, que tem o objetivo de assegurar a proteção dos afluentes do rio Verde.

O roteiro passa pela pequena sede urbana do município, que dista aproximadamente $10 \mathrm{~km}$ de Curitiba. Os acessos principais são pelo Contorno Norte - ligação entre as regiões Sul e Sudeste do Brasil - e a PR-090, Estrada do Cerne, que é a continuação da Avenida Manoel Ribas - principal avenida do bairro Santa Felicidade em Curitiba. O itinerário tem uma extensão total de $42 \mathrm{~km}$.

Os empreendimentos deste roteiro estão organizados através da ATCM. Essa associação possui sede itinerante, que atualmente fica na sede do 'Restaurante Pedra Chata' Cada presidente mantém, durante sua gestão, a documentação da associação em seu próprio estabelecimento. As reuniões ocorrem de forma alternada nos empreendimentos associados. A estratégia de também fazer reuniões itinerantes permite que os associados do roteiro conheçam os empreendimentos participantes. Isso fortalece o grupo, uma vez que estas se encerram com uma pequena confraternização, geralmente organizada pelo anfitrião da vez.

O roteiro atualmente compreende 27 atrativos (quadro I), sendo exploradas as características culturais das colonizações polonesa e italiana - arquitetura, artesanato, museu e gastronomia -, porém suas características mais fortes são as ecológicas - cachoeiras, lagos, morros, agroecologia e atividades ao ar livre. Apenas nove emprendimentos estão filiados à associação, todos estes se enquadram na categoria atrativos produtivos. 


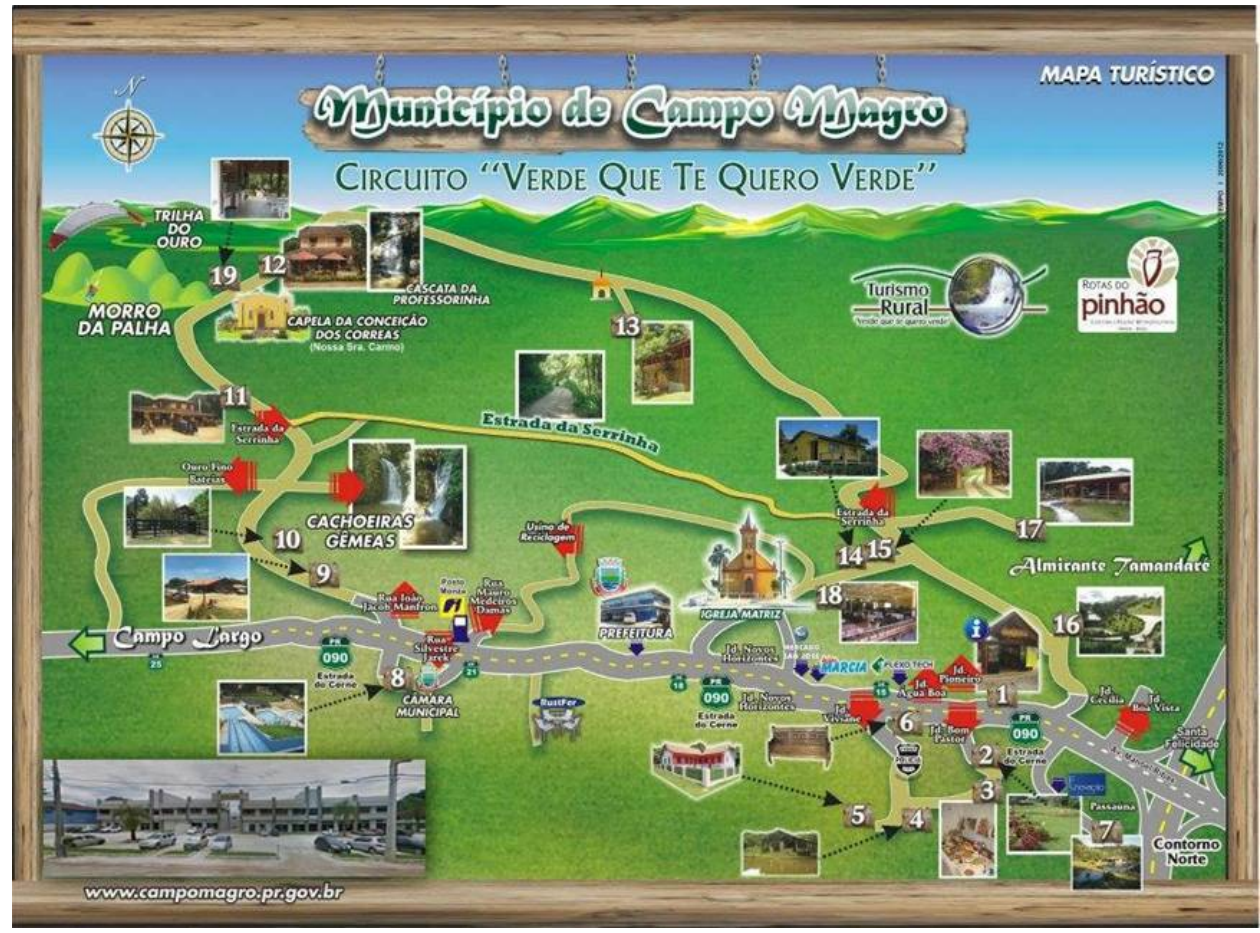

Fig. 2 - Roteiro de turismo rural 'Verde Que te Quero Verde’ de Campo Magro. Figura a cores disponível online.

Fig. 2 - Rural Tourism Route 'Verde Que te Quero Verde' of Campo Magro. Colour figure available online.

Fonte: www.campomagro.pr.gov.br

O roteiro conta com cinco atrativos naturais, como cachoeiras e cascatas, morros e lagoa. Destes, apenas o Morro da Palha é explorado. Trata-se de um local de referência em voo livre no estado do Paraná com 1 080m de altitude em relação ao nível do mar e $300 \mathrm{~m}$ de desnível em relação ao pouso. A sede do Clube do Palha - atrativo produtivo conta com pista de pouso, além de ampla área verde com bosque para acampamento, banheiros e restaurante. A Estrada da Serrinha atravessa o interior do município numa extensão de $6 \mathrm{~km}$, destacando-se pela sua beleza cênica. Ela é muito frequentada pelos praticantes de off road e motocross.

A Trilha do Ouro é considerada um atrativo tanto como cultural como naturaliii. Ela acompanha o curso do rio Conceição, seguindo os vestígios da história do ouro de Campo Magro. Entre os atrativos culturais tem-se: museu, igrejas, cruzeiro e antigas edificações. Os imigrantes, sobretudo os poloneses, construíam capelas de madeira ou cruzes nas entradas das colônias - como na Dom Pedro II - para fazerem suas rezas (Sikora, 2014). Remanescentes na paisagem local têm-se a antiga casa da Farinheira do Sr. Adílio Santana e um Forno de Cal desativado. 
Quadro I - Atrativos do roteiro "Verde Que te Quero Verde".

Table I - Attractions of the Route 'Verde Que te Quero Verde'.

\begin{tabular}{|c|c|c|}
\hline Tipo & Atrativo & Sócio/Não sócio \\
\hline \multirow{5}{*}{ Natural } & Cachoeiras Gêmeas & \multirow{12}{*}{ Não sócio } \\
\hline & Cascata da Professorinha & \\
\hline & Morro da Palha & \\
\hline & Lagoa Azul/Parque das Pedreiras & \\
\hline & Estrada da Serrinha & \\
\hline \multirow{7}{*}{ Cultural } & Trilha do Ouro & \\
\hline & Museu do Lixo & \\
\hline & Igreja Matriz Imaculada Conceição & \\
\hline & Capela Nossa Senhora do Carmo & \\
\hline & Cruzeiro da Colônia D. Pedro II & \\
\hline & Farinheira Sr. Santana (casa antiga) & \\
\hline & Forno de Cal (forno antigo) & \\
\hline \multirow{13}{*}{ Produtivo } & Bar do Paulo & \multirow{9}{*}{ Sócio } \\
\hline & Pesqueiro e Parque Aquático do Rei & \\
\hline & Recanto Sagrado (sítio pedagógico) & \\
\hline & Mangala Ekos (eventos) & \\
\hline & Chácara Santana (lazer e eventos) & \\
\hline & Restaurante Novo Casarão & \\
\hline & Restaurante Nova Polska & \\
\hline & Restaurante Pedra Chata Ecológico & \\
\hline & Restaurante Pedra Sobre Pedra & \\
\hline & Recanto Nativo (produção de orgânicos) & \multirow{4}{*}{ Não sócio } \\
\hline & Sítio do Serelepe & \\
\hline & Café Colonial Vovó Bruna & \\
\hline & Clube do Palha (clube de voo livre) & \\
\hline \multirow{2}{*}{ Técnico, Científico e Artístico } & Observatório Astronômico do Colégio Estadual do Paraná & \multirow{2}{*}{ Não sócio } \\
\hline & Usina de Valorização de Recicláveis & \\
\hline
\end{tabular}

Fonte: Pesquisa de campo das autoras

Atrativos produtivos ou econômicos também compõem o roteiro, tais como: chácara de orgânicos, pesqueiro, parque aquático, chácaras de eventos, restaurantes e café colonial. Há ainda atrativos de cunho técnico e científico que recebem visitas agendadas: o Observatório Astronômico e a Usina de Valorização de Recicláveis ${ }^{\text {iv }}$. O Museu do Lixo, atrativo cultural que expõe objetos curiosos que as pessoas jogam fora, faz parte do complexo da Usina. 
O roteiro 'Verde Que te Quero Verde' recebe ainda diversos eventos (quadro II) que são promovidos por entidades de fora do roteiro, mas que fomentam sua visitação.

Quadro II - Eventos programados no roteiro 'Verde Que te Quero Verde'.

Table II - Planned Events of the Route 'Verde Que te Quero Verde'.

\begin{tabular}{ll}
\hline Evento & Mês \\
\hline Festa da Batatinha & Junho \\
Pedalada Internacional na Natureza & Junho \\
Caminhada Internacional na Natureza & Outubro \\
Caminhada da Lua Cheia & Outubro \\
Encontro de Trilheiros & Outubro \\
Campeonatos de Voo Livre & Anual \\
\hline
\end{tabular}

Fonte: Pesquisa de campo das autoras

A Festa da Batatinha é característica do município e realizada anualmente, após a colheita, pela igreja Nossa Senhora da Conceição. Esta festa ainda se restringe ao âmbito municipal, demonstrando que precisa passar por amadurecimento para atingir outros públicos. Todavia, seu foco está na valorização da cultura local, que fortalece a identidade da comunidade e do roteiro.

A Emater (Instituto Paranaense de Assistência Técnica e Extensão Rural) e Prefeitura Municipal de Campo Magro, juntamente com a ATCM, organizam caminhadas e pedaladas ecológicas de maneira que seus percursos passem pelas propriedades rurais e por alguns atrativos. Alternam-se os percursos a cada evento para contemplar a maioria dos empreendimentos. Esses eventos, além de fortalecerem a agricultura familiar, divulgam o roteiro de turismo. Esses eventos se inserem no calendário estadual de Caminhadas Internacionais na Natureza da Emater.

A Caminhada da Lua Cheiav é outro evento ao ar livre realizado pela Prefeitura do Município no roteiro. A concentração dos participantes ocorre no final da tarde no restaurante Pedra Chata Ecológico e o percurso tem $10 \mathrm{~km}$ de extensão. $\mathrm{O}$ trajeto, considerado de esforço físico moderado, é todo sinalizado. Encontros de trilheiros são organizado pela DNA Trilheiros (Ong com sede em Campo Magro) com chancela da Federação Paranaense de Motociclismo. Tais eventos atraem participantes provenientes da região Sul do país e de estados como Minas Gerais e São Paulo, além de paraguaios ${ }^{\mathrm{vi}}$. O ponto de encontro desses eventos é o Bar do Paulo ou a sede do Clube do Palha, locais estratégicos para jipeiros, trilheiros e praticantes do voo livre.

Os eventos de voo livre acontecem ao longo do ano no Morro da Palha. O roteiro já recebeu etapa do Campeonato Paranaense de Parapente e o Rock Fly, que é uma realização do Clube do Palha com apoio da prefeitura local. Quando esses eventos ocorrem, intensificam-se as visitações nos diferentes atrativos do roteiro, ampliando a abrangência da origem dos turistas para o Brasil inteiro.

A exploração de atrativos - naturais, culturais, produtivos, técnico-científicos e artísticos -, aliados aos eventos realizados, vem fomentando as atividades turísticas no muni- 
cípio de Campo Magro nos últimos 10 anos. Assim, observa-se que a governança do roteiro 'Verde Que te Quero Verde' vem imprimindo no município contornos do que se concebe como desenvolvimento territorial.

\section{Construção metodológica da pesquisa}

Para a efetivação do estudo de caso, a pesquisa de campo constituiu-se primeiramente de observação estruturada no roteiro turístico 'Verde Que te Quero Verde' de Campo Magro. Foram realizadas visitações ao roteiro, seus atrativos e eventos, bem como, conversas informais com empreendedores e visitantes.

Após esta aproximação à realidade, foram construídos instrumentos de pesquisa roteiros das entrevistas - com base nas reflexões teóricas empreendidas em torno das articulações entre roteirização turística e desenvolvimento territorial. Três elementos dessas articulações foram selecionados:

a) Planejamento e Gestão, ou seja, como a roteirização turística leva a redefinição ou adaptação dos sistemas produtivos anteriores e ao planejamento e gestão das novas atividades: foram levantadas informações que permitissem um diagnóstico da dinâmica econômica local, bem como, do sistema de governança;

b) Relações com o Aglomerado Urbano de Curitiba em virtude de fatores locacionais, como a proximidade de forte potencial consumidor: foram avaliados as características e o comportamento dos visitantes e turistas do roteiro;

c) Impactos do turismo: considerando que um sistema contínuo de monitoria e avaliação permite verificar a eficácia das ações desenvolvidas e os possíveis impactos - positivos e negativos - causados pelo turismo, levantaram-se informações sobre os efeitos ambientais, socioculturais e econômicos do roteiro.

As entrevistas em profundidade, em número de sete, foram realizadas com empreendedores da associação, bem como com representantes do poder público, comunidade local e visitantes (quadro III).

Quadro III - Caracterização dos entrevistados no roteiro 'Verde Que te Quero Verde'.

Table III - Profile of the interviewed partners on the route 'Verde Que te Quero Verde'.

\begin{tabular}{lll}
\hline Gênero & Função do entrevistado no roteiro & Identificação* \\
\hline Masculino & Presidente da Associação (2016) e empreendedor & ASS 1 \\
Masculino & Presidente da Associação (2018) e empreendedor & ASS 2 \\
Feminino & Representante Poder Público (2012) & PPL 1 \\
Masculino & Representante Poder Público (2018) & PPL 2 \\
Feminino & Comunidade local & COM 1 \\
Feminino & Visitante & VIS 1 \\
Masculino & Visitante & VIS 2 \\
\hline
\end{tabular}

As entrevistas foram realizadas entre 2016 e 2019, sendo gravadas e posteriormente transcritas. Os resultados destas são apresentados e discutidos na próxima seção. 


\section{O DESENVOLVIMENTO TERRITORIAL COMO DIMENSÃO DE ANÁLISE: RESULTADOS E DISCUSSÕES}

Analisa-se, na sequência, o roteiro de turismo rural 'Verde Que te Quero Verde' a partir de uma de suas dimensões, a do desenvolvimento territorial. Os três eixos selecionados estruturam a análise, que tem por base, sobretudo, o conteúdo das entrevistas.

\section{Planejamento e gestão}

Antes de se iniciarem os primeiros empreendimentos ligados ao turismo, o sistema produtivo em Campo Magro era baseado exclusivamente em atividades agropecuárias. As atividades turísticas foram sendo gradativamente introduzidas, se agregando às atividades econômicas anteriores. Há casos em que estas foram mantidas apenas para viabilizar o consumo da própria família, passando o turismo a ser a principal atividade de rendimento, todavia, foram poucos os empreendimentos que abandonaram totalmente a agropecuária (PPL 1; ASS 1).

Empreendedores de turismo ainda mantêm atividades agropecuárias em suas propriedades e alguns eventos demonstram claramente as raízes e a manutenção da ruralidade no roteiro 'Verde Que te Quero Verde'. Assim, a vinculação do turismo ao sistema produtivo anterior revela a preocupação em se aproveitar o potencial endógeno local, pautado na sua ruralidade. Revela ainda o potencial articulador e indutor de desenvolvimento do turismo.

Cada empreendimento teve iniciativa própria para abrir as portas na fase inicial, sem um planejamento coletivo prévio do roteiro. As primeiras reuniões para articulação do roteiro ocorreram entre 1997 e 1998. Essa iniciativa teve o apoio do poder público e do Sebrae com a criação de redes de cooperação (ASS 1; ASS 2; PPL 1; PPL 2). A associação do roteiro foi instituída oficialmente apenas em 2003 (PMCM; Uninter, 2012). Com passar dos anos a associação ganhou forças e houve abertura de novos empreendimentos, bem como a busca de melhorias nos já existentes.

Aos poucos foram também sendo desenvolvidos sistemas de parceria, exemplo disso foi a realizada com Associação de Indústria e Comércio do Município de Campo Magro para instalação da nota fiscal eletrônica nos empreendimentos. O roteiro já teve parceria com Senar (Serviço Nacional de Aprendizagem Rural), que ministrou oficinas de formação. O Sebrae organizou os empreendedores de toda a Região Metropolitana de Curitiba em torno da Rota do Pinhão ${ }^{\text {vii }}$ para elaboração de folder e site (PPL 1). Já existiu uma parceria informal com Grupo de Agroecologia do município, que auxiliou na preparação do café da manhã das Caminhadas. Teve a parceria com uma Instituição de Ensino Superior - a Uninter - para a elaboração do inventário da oferta turística. Atualmente tem-se parceria com a Emater para a realização dos eventos Caminhada e Pedalada Internacional na Natureza (PPL 1, PPL 2).

Alguns estudos de viabilidade técnica do roteiro foram realizados ao longo dos anos, entre eles (PPL 2): a Análise do Potencial Turístico de Campo Magro de 2002; o Plano de Desenvolvimento Turístico de Campo Magro seguido do Inventário Turístico 2004/2005; a 
Pesquisa de Demanda realizada em 2006 e o Inventário da Oferta Turística 2011-2012. Tais estudos, em geral, foram fomentados a partir de políticas nacionais e estaduais vinculadas a programas de municipalização do turismo, num primeiro momento, e de roteirização deste, num momento posterior. A execução dos estudos também foi, em parte, fruto de parcerias.

Com relação à infraestrutura, o roteiro se fortaleceu, sobretudo, após a criação da associação. Atualmente o roteiro não possui posto de Informação Turística, mas este esteve ativo entre 2006 e 2012. O acesso à rede de internet permitiu que os empreendedores pudessem oferecer aos turistas e visitantes o sistema de cartão para pagamentos. A sinalização turística foi instalada pela prefeitura entre os anos de 2005 e 2006 . As placas, entretanto, estão ainda apenas nas principais vias de acesso ao roteiro. Um desejo da associação é estabelecer uma sinalização padronizada em frente de cada atrativo com um mapa de localização para auxiliar o usuário. Atualmente estuda-se se implantar postos de informações turísticas dentro de cada empreendimento associado (ASS 1, ASS 2).

A associação é responsável por diversas conquistas. Foi relatada a da revitalização da Estrada do Cerne, que é a principal via de acesso ao roteiro. Outra conquista mencionada foi a cozinha de agroindústria do agricultor, cozinha comunitária equipada para o bene-

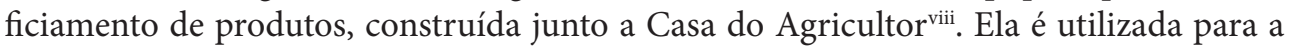
produção de pães, doces, geleias e armazenamento das verduras cultivadas pelos agricultores (ASS 2).

A associação se mantém financeiramente com mensalidades fixas dos sócios. Todos pagam o mesmo valor, independente da natureza do estabelecimento. Os associados participam da entidade por meio de reuniões, assembleias e eventos. Cada associado participa de maneira específica nos eventos, mas em geral cada um instala seu quiosque para a venda de produtos. A associação tem representatividade no Conselho Municipal de Turismo (Comtur), órgão consultivo e de assessoramento do poder executivo local, que tem por objetivo opinar, sugerir, indicar e propor medidas que tenham por finalidade o desenvolvimento da atividade turística no município (ASS 2; PPL 2).

O principal meio de divulgação formal do roteiro é o folder. A associação tem dificuldade em abastecer continuadamente o site com informações e pretendem arrumar um parceiro para isso. No folder atual foi estabelecido um sistema de fidelização do roteiro: a cada empreendimento visitado o cliente ganha carimbo e desconto de $20 \%$ na conta (ASS 1; ASS 2; PPL 2). A divulgação do roteiro ocorre, sobretudo, de maneira informal por meio de quem o visita. Quando o roteiro aparece em reportagens televisivas, observa-se um alavancar significativo no fluxo de visitação. As Caminhadas Internacionais na Natureza, eventos de maior porte, também ajudam a divulgar o roteiro (ASS 1; ASS 2; PPL 1; VIS 1; VIS 2).

A capacitação do pessoal envolvido nas atividades de turismo é uma forte aliada na qualificação do roteiro (ASS 1; ASS 2; PPL 1; PPL 2). Vem se procurando oferecer uma diferenciação dos produtos e serviços oferecidos e também novas alternativas de lazer (PPL 1; ASS 2). Existe potencial para agregar outras atividades da comunidade ao roteiro, sobretudo as relacionadas às festividades ofertadas nos clubes e as igrejas locais (ASS 2). 
A partir da criação da associação no roteiro, várias ações vêm sendo empreendidas. Têm-se cursos de capacitação para empreendedores e trocas de experiências vivenciais com integrantes de associações de outros roteiros da região. Sobre a mão de obra utilizada nos empreendimentos, foi levantado que todos os empreendimentos atuam com mão de obra familiar, sendo que a maioria destes também emprega mão de obra externa. Os restaurantes e chácaras de eventos funcionam com mão de obra mista e pagamento em diárias, visto que a maioria só atende aos finais de semana e feriados (ASS 1; ASS 2; PPL 1; PPL 2).

Sobre as transformações ocorridas nos empreendimentos individuais após a implantação da associação do roteiro, foram revelados pontos positivos. A organização coletiva trouxe estímulos para que os empreendedores investissem e se preparassem para o turismo (ASS 1; ASS 2). É consenso entre os entrevistados (ASS 1; ASS 2; PPL 1; VIS 1; VIS 2), que não existe concorrência entre os empreendimentos dentro do roteiro. Um empreendedor ajuda o outro sempre que preciso e a associação fortalece a união e boa relação entre os associados.

Observa-se nas informações prestadas pelos diferentes atores entrevistados que há autonomia por parte dos empreendedores de turismo na gestão e planejamento do roteiro. Papel importante neste sentido é o da autogovernança exercida pela ATCM, que além de dinamizar a organização dos empreendores em prol de ações conjuntas, estabelece o canal de comunicação entre o grupo e os órgãos públicos de fomento.

\section{Relações com o Aglomerado Urbano de Curitiba}

A proximidade do roteiro de turismo rural 'Verde Que te Quero Verde' em relação ao Aglomerado Urbano de Curitiba é considerada um fator extremamente positivo para suprir a demanda turística local. Uma pesquisa sobre esta demanda (PMCM; Uninter, 2012), a partir dos dados do posto de Informação Turística do roteiro, revelou que a maioria de seus visitantes são oriundos de Curitiba. Atualmente o roteiro não tem um controle de entrada de visitantes, mas aproximadamente $80 \%$ dos visitantes são provenientes de Curitiba (ASS 2).

Como se trata de um roteiro rural, os fatores climáticos influenciam na atração do público. O movimento de turistas cai em dias chuvosos para empreendimentos como restaurantes, café, chácaras de lazer e venda de produtos orgânicos (PPL 2). Porém, o público de aventura - como os jipeiros e trilheiros - aprecia tempo chuvoso e barro (ASS 1).

De acordo com o Inventário Turístico (PMCM; Uninter, 2012), o roteiro 'Verde que te Quero Verde' é normalmente visitado por casais com família e/ou amigos. Eles procuram serviços de gastronomia, áreas de lazer e atrativos naturais. A faixa etária dos visitantes concentra-se entre 21 e 40 anos. Em 2012 estima-se que aproximadamente 18 mil visitantes por mês chegavam a Campo Magro durante o período de alta temporada, que compreende aos meses entre setembro e maio. $\mathrm{O}$ meio de transporte predominantemente utilizado é o carro particular. Mesmo os trilheiros, em sua maioria, frequentam o roteiro com a família no carro e levam as motos no reboque para usar apenas dentro do roteiro. Atualmente é visível também um grande número de ciclistas visitando o roteiro pela facilidade de acesso pela Estrada do Cerne revitalizada (PPL 1; PPL 2). 
O marketing é um instrumento essencial ao processo de roteirização. Existem técnicas que permitem auxiliar os produtores de bens e serviços no sentido de permitir que o resultado de sua produção satisfaça as necessidades e as expectativas dos consumidores. Os visitantes e turistas tem acesso às informações sobre o roteiro, percurso e atrativos, por meio de folders, mas também através de internet, reportagens televisivas e principalmente no "boca a boca". Apesar de o público principal ser advindo de Curitiba, não é feito um trabalho específico de divulgação nessa capital. A divulgação direta aos moradores do Aglomerado Urbano de Curitiba ocorre apenas nas participações em feiras e exposições com a distribuição de folders. A associação não possui parcerias com agências de turismo de Curitiba que poderiam fazer a articulação entre a oferta e a demanda (PPL 1; ASS 1; ASS 2).

O roteiro já foi bastante divulgado na Feira dos Sabores que a Emater com a Secretaria da Agricultura e do Abastecimento do Paraná (Seab) promoviam em Curitiba, porém a feira foi cortada do calendário de eventos pela atual gestão estadual. Os visitantes dessa feira eram um público que valorizava o que o produtor fazia. Atualmente quem faz esse papel de divulgação em Curitiba é apenas a Chácara de Orgânicos, que comercializa semanalmente seus produtos na feira hortifrutigranjeira do Passeio Público (PPL 1).

Não se tem uma estimativa de qual o gasto médio do visitante no consumo das ofertas do roteiro visto que este é bastante variado e não há seu registro. Há potencialidade para aumento do número de turistas no roteiro, bem como aumento do número de empreendimentos, com uma maior diversificação da oferta turística no roteiro (PPL 2).

$\mathrm{Na}$ Lagoa Azul está para ser implantado o Parque das Pedreiras, composto por uma área de $140000 \mathrm{~m}^{2}$ com centro gastronômico, centro de convenções, centro de exposições e uma escola ecológica. Trata-se de um projeto privado de 43 milhões de reais já aprovado pelo Ministério do Turismo. O financiamento da obra será do Banco Nacional de Desenvolvimento Econômico e Social (BNDES). A estimativa é que seja o segundo maior projeto de turismo do Paraná, perdendo apenas para o Parque Nacional do Iguaçu. Com sua implantação a expectativa é de estimular abertura de mais 20 empreendimentos, além de gerar mais de 1000 empregos diretos (PPL 2; ASS 2).

A singularidade do roteiro 'Verde Que te Quero Verde' encontra-se nos atrativos naturais e no estilo de vida dos moradores locais, diferentes da realidade dos grandes centros (ASS 1; PPL 1; PPL 2). Essas características tornam o roteiro atrativo, sobretudo, para visitantes advindos do Aglomerado Urbano de Curitiba. Neste sentido, ao contemplar princípios orientadores das práticas territoriais de turismo, como é o caso da valorização do patrimônio natural e das trocas culturais, o roteiro direciona um fluxo de visitantes próximos que buscam experiências diferentes do cotidiano urbano que vivenciam.

\section{Impactos do turismo na localidade}

Comumente, a identificação dos impactos de um roteiro faz parte do sistema de monitoria e avaliação do mesmo. Os impactos podem ser positivos e negativos. Com relação a sua natureza, estes podem ser classificados em ambientais, socioculturais e/ou 
econômicos. Neste tópico são apresentados os impactos percebidos pelos atores locais após a implantação do roteiro.

Como o município de Campo Magro está localizado em áreas de mananciais e proteção ambiental, o roteiro 'Verde Que te Quero Verde’ já nasceu com o viés da conservação. O próprio nome do roteiro dá identidade ao município e o coloca na posição de sustentabilidade e preservação:

"O turismo ameniza a imagem negativa que as pessoas têm do município. Em Campo Magro o nome do roteiro passou ser referência para o município tipo 'a você é de Campo Magro onde tem bastante verde?' O nome do roteiro pegou. Mesmo a gente escutando criticas tipo, onde é que está o verde? (...) as propriedades não são sustentáveis." (PPL 1).

Apesar de pertencerem à Prefeitura Municipal de Curitiba, a Usina e o Museu do Lixo estão localizados no roteiro e propiciam conscientização por meio de palestras sobre educação ambiental, viabilização do processo de reciclagem de resíduos sólidos, além de visitas acompanhadas (PMCM; Uninter, 2012). Existe ainda neste roteiro um sistema de coleta de lixo com frequência semanal e reciclagem mensal, no qual cada estabelecimento é responsável pela separação ${ }^{\text {ix }}$. Neste sentido, o turismo apresenta-se como um aspecto positivo, pois para garantir a conservação da paisagem se criaram mecanismos de minimização de seus impactos no meio ambiente, pelo menos no que diz respeito à destinação dos resíduos que proporciona.

Nota-se a preocupação com a natureza até mesmo na forma de divulgação do roteiro, que chama o turista a visitá-lo e já o lembra da importância de preservar: "É uma honra receber visitantes que busquem a harmonia no contato com a natureza lembrando sempre que a sua conservação depende de todos nós. Venha conhecer o circuito 'Verde Que te Quero Verde' de turismo rural em Campo Magro e traga sua família!"x

Sobre os aspectos socioculturais positivos é enfatizado o reconhecimento da própria população enquanto cidadã campomagrense e da valorização dos produtores rurais:

"A questão da identidade do município enquanto munícipe campomagrense (...). O pessoal da área rural já tem um pouco mais essa questão da valorização da identidade e do campo mesmo, não tem mais vergonha. O pessoal que começou a trabalhar com turismo você vê que eles superaram muito aquela dificuldade do agricultor de sair da lavoura e entrar atrás de um balcão de venda e lidar com o turista. Eles se sentiam muito acuados. Essa questão da identidade, mesmo nas reuniões da associação, hoje você vê eles superarticulados, com conhecimento de causa (...)." (PPL 1).

No que se refere aos impactos econômicos positivos foram apontadas a ampliação e diversificação das atividades turísticas com a implantação do roteiro, o que resultou no aumento da empregabilidade para a comunidade local. Com a intensificação do fluxo de visitantes houve também o aumento do consumo de bens e serviços em geral, contribuindo para a maior geração de renda nos empreendimentos. Com a consolidação do roteiro, os moradores não precisaram mais sair da localidade para conseguir emprego e melhor qualidade de vida (ASS 1). 
O envolvimento da nova geração nos empreendimentos vem garantindo a permanência de seus integrantes na propriedade e a continuidade nas atividades turísticas dos estabelecimentos:

"Os filhos se envolvendo nos empreendimentos turísticos dos pais como no Pesque Pague que o filho é zootecnista e administra a parte dos tanques, no Pedra Chata é o filho (...) que toca, no Nova Polska também é o filho, o Pedra Sobre Pedra também tem a filha se envolvendo, Bar do Paulo também (...) grande parte está ficando na propriedade." (ASS 2).

Contudo, o turismo não traz apenas impactos positivos. São relatados diversos exemplos de mau uso dos recursos ambientais do roteiro, sobretudo pelos jipeiros e trilheiros:

“(...) principalmente os trilheiros faziam impacto muito grande nas trilhas. Os motociclistas invadiam a área das Cachoeiras Gêmeas e destruíam a trilha de acesso até as cachoeiras de forma que, às vezes, os pedestres não conseguiam passar. As invasões não eram em propriedades do circuito, eram de outras propriedades particulares." (PPL 1).

Estes visitantes proporcionam degradação ambiental nas trilhas, além de deteriorar as estradas de chão que são compartilhadas com a comunidade local, que se incomoda com a poeira e o barulho dos jipes e motos nos finais de semana (COM 1). "É muito perigoso também, eles são abusados. Se acham donos da estrada", desabafa uma moradora (COM 1). A comunidade está se articulando para solicitar pavimentação e colocação de lombadas para redução da velocidade, na tentativa de amenizar o conflito.

Assiste-se, portanto, a uma situação de conflito entre aventureiros e comunidade local, que expressa uma necessidade urgente de intervenção para compartilhamento tranquilo entre as partes.

"Motoqueiro e jipeiro acha que é turista e não é. Só impacta. Nós trabalhamos a semana
toda pra arrumar as estradas e eles num dia destroem tudo. O Munícipe reclama. Eles
passam a 70km por hora e enchem a cara do morador de pó. Tratam mal os moradores.
Nós queremos fazer com que eles tenham conscientização com a população. Nós que-
remos fazer o jipeiro entender que a estrada não é só deles. Queremos que haja um
compartilhamento." (PPL 2).

Outro aspecto negativo diz respeito aos impactos econômicos. Foi mencionada a questão da especulação imobiliária, principalmente na região da estrada da comunidade Ouro Fino, que se caracteriza por sua beleza natural. Com a revitalização da ligação pela Estrada do Cerne houve o aumento do preço das propriedades. Com isso, assiste-se a saída dos antigos moradores pela venda de suas terras, o que fragiliza as ações coletivas, já que os novos proprietários não estão vinculados à história e cultura local (PPL 1).

Uma sinopse dos impactos do turismo no roteiro 'Verde Que te Quero Verde' é apresentado no quadro IV. 
Quadro IV - Impactos positivos e negativos do turismo no roteiro 'Verde Que te Quero Verde'.

Table IV - Positive and negative impacts of tourism on the Route 'Verde Que te Quero Verde'.

\begin{tabular}{lll|lll}
\hline \multicolumn{3}{c|}{ POSITIVOS } & \multicolumn{3}{c}{ NEGATIVOS } \\
\hline Ambientais & Socioculturais & Econômicos & Ambientais & Socioculturais & Econômicos \\
\hline $\begin{array}{l}\text { Coleta seletiva } \\
\text { de lixo }\end{array}$ & $\begin{array}{l}\text { Imagem de } \\
\text { identidade }\end{array}$ & $\begin{array}{l}\text { Valorização dos } \\
\text { produtos rurais }\end{array}$ & Lixo & Invasões & $\begin{array}{l}\text { Especulação } \\
\text { imobiliária }\end{array}$ \\
\hline & $\begin{array}{l}\text { Manutenção da } \\
\text { família no } \\
\text { empreendimento }\end{array}$ & $\begin{array}{l}\text { Diversificação e } \\
\text { ampliação das atividades } \\
\text { econômicas }\end{array}$ & Erosão nas trilhas \\
\hline & Geração de renda & $\begin{array}{l}\text { Degradação das } \\
\text { estradas }\end{array}$ \\
\hline & Geração de emprego & & \\
\hline
\end{tabular}

Fonte: Entrevistas realizadas pelas autoras

A construção de uma imagem turística ao município a partir de suas características ambientais e socioculturais, bem como, a integração das novas atividades as atividades agropecuárias preexistentes, levaram não só a valorização dos produtores rurais, como também a geração de renda e emprego, propiciando alternativas às novas gerações. Todavia, a convivência com visitantes e turistas não se realizou sem problemas, com eles veio a degradação ambiental, os conflitos socioculturais e a especulação imobiliária associada à expulsão de antigos moradores.

\section{CONSIDERAÇÕES FINAIS}

A transformação produtiva de certas zonas rurais mantendo nelas seus moradores e, mais que isso, melhorando as condições e qualidade de vida desses, como aponta Meyer (2004), é uma das metas perseguidas na roteirização turística, além de se constituir em importante indicador do desenvolvimento territorial defendido por Veiga (2002). Assim, pode-se afirmar que a agregação de atividades de turismo ao sistema produtivo local de base agropecuária permitiu ao roteiro 'Verde Que te Quero Verde’ tornar-se um instrumento indutor de desenvolvimento endógeno e territorial na zona rural do município de Campo Magro. Tal indução se tornou viável, sobretudo, por sua localização estratégica no entorno do Aglomerado Urbano de Curitiba, equilibrando oferta e demanda às atividades turísticas.

Para tal transformação social positiva, papel importante desempenhou o sistema de autogovernança de caráter autonomo, defendido por Souza (2013). A associação de turismo criada em torno do roteiro 'Verde Que te Quero Verde', bem como a integração desta a uma ampla rede externa de cooperação formada por organizações governamentais e não governamentais, contribuiu para gerar uma dinâmica produtiva, com competitividade e sustentabilidade, que articulou a economia de seu território para mercados alternativos, ou seja, não apenas voltados à agropecuária e ao turismo convencional. 
Neste contexto, o turismo rural articulado no roteiro se apresentou como um instrumento versátil de desenvolvimento territorial à medida que potencializou os recursos naturais e culturais do município.

\section{AGRADECIMENTOS}

Agradecemos aos/às senhores/as: José Mauro da Assunção Vallim, Eros Consentino Tozetto, Edinilson Maeski, José Nilceu Kadlubiski, Aline Martinhago, Josiane Schroeder Dal Santos e Arlete Klaina pela concessão das entrevistas e material de apoio a pesquisa; ao LAGEO - Laboratório de Pesquisas Aplicadas em Geomorfologia e Geotecnologias da UFPR pela elaboração do mapa de localização de Campo Magro - PR; a Wolf-Dietrich Sahr e Sidney Vikou pelas traduções de inglês e francês respectivamente; e ao CNPq pela concessão de bolsa de pesquisa a primeira autora.

\section{REFERÊNCIAS BIBLIOGRÁFICAS}

Bahl, M. (2004). Viagens e roteiros turísticos [Travels and tourist routes]. Curitiba: Protexto.

Brambatti, L. E. (Org). (2002). Roteiros de Turismo e Patrimônio Histórico [Tourist routes and historical heritage]. Porto Alegre: EST Edições.

Cooper, C., Hall, C. M., Trigo, L. G. G. (2011). Turismo Contemporâneo [Contemporary Tourism]. Rio de Janeiro: Elsevier.

Figueira, L. M. (2013). Roteirização do turismo: uma abordagem preliminar à "apresentação-interpretação" do território [Route development in tourism: a preliminary approach to the "presentation-interpretation" of territory]. Revista Turismo \& Desenvolvimento, 20, 121-133.

Instituto de Pesquisa Econômica Aplicada/Instituto Paranaense de Desenvolvimento Econômico e Social. (IPEA/IPARDES). (2013). Caracterização e Quadros de Análise Comparativa da Governança Metropolitana no Brasil: Arranjos Institucionais de Gestão Metropolitana - Região Metropolitana de Curitiba [Characterization and comparative analytical scheme of metropolitan governance in Brazil: Institutional clusters of metropolitan government - the Metropolitan Region of Curitiba]. Brasília: IPEA. Retrieved from http://www.ipea.gov.br/redeipea/images/ pdfs/governanca_metropolitana/rel1_1_rmc. pdf

Meyer, D. (2004). Tourism routes and gateways: key issues for the development of tourism routes and gateways and their potential for pro-poor tourism. London: Overseas Development Institute.

Moletta, V. (2002). Comercializando um destino turístico [Marketing of a tourist destination]. Porto Alegre: Mercado Aberto.

Prefeitura Municipal de Campo Magro/Centro Universitário Internacional. (PMCM/Uninter). (2012). Inventário da Oferta turística de Campo Magro 2011-2012 [Inventory of tourist supply in Campo Magro 2011-2012]. Campo Magro: PMCM/ Uninter.

Paraná Turismo/Serviço Brasileiro de Apoio às Micro e Pequenas Empresas. (PRTUR/Sebrae). (2014). Paraná - estudo estatístico 20 anos de turismo [Paraná - statistical study 20 years of tourism]. Curitiba: PRTUR/Sebrae.

Scherer, L. (2014). Roteirização turística no espaço rural: estudo longitudinal da Rota Colonial Baumschneis - Dois Irmãos, Rio Grande do Sul [Touristic route planning in rural areas: longitudinal study on the Colonial Baumschnies Route - Dois Irmãos, Rio Grande do Sul]. 269 f. (Dissertação de Mestrado). Universidade de Caxias do Sul, Caxias do Sul, Brasil.

Sikora, M. A. (2014). As políticas de imigração no Brasil nos séculos XIX e XX e o desenvolvimento de territórios: Estudo de Caso da Colônia Dom Pedro II - (Campo Largo - Paraná) [Immigration policies of Brazil in the 19th and 20th century and the development of territories - A case study of the settlement colony Dom Pedro II (Campo Largo 
- Paraná)]. (Dissertação de Mestrado) Universidade Tecnológica Federal do Paraná, Curitiba.

Silva, J. A. S. (2006). A Dimensão Territorial no Planejamento do Desenvolvimento Turístico no BrasiI: modelo do pólo de crescimento versus modelo territorialista e endógeno [The territorial dimension in tourist development planning in Brazil growth pole model versus territorial and endogenous model]. Turismo em Análise, 17, 5-23.
Souza, M. L. de (2013). Os conceitos fundamentais da pesquisa sócio-espacial [Fundamental concepts of socio-spatial research]. Rio de Janeiro: Bertrand Brasil.

Tavares, A. M. (2002). City tour. São Paulo: Aleph.

Veiga, J. E. da (2002). A face territorial do desenvolvimento [The territorial side of development]. Revista Internacional de Desenvolvimento Local, 3(5), 5-19.

i Segundo a Coordenação da Região Metropolitana de Curitiba (Comec), na Região Metropolitana de Curitiba se apresentam duas diferentes agregações: a) a Região Metropolitana de Curitiba propriamente dita, formada por 29 municípios; b) o Aglomerado Urbano de Curitiba, formado por 14 municípios que congregam a mancha urbanizada no entorno de Curitiba (Ipea/Ipardes, 2013). O presente estudo se pauta na segunda destas agregações.

ii Este último roteiro abrange também área do município de Campo Magro.

iii Ver inventário turístico do município (PMCM; Uninter, 2012).

iv Esta usina foi criada em 1990 com objetivo de fomentar a prática da reciclagem pela triagem dos resíduos sólidos reaproveitáveis. Estes resíduos são coletados pela Prefeitura de Curitiba. Desde 1998 o Instituto Pró Cidadania de Curitiba (IPCC) administra da usina e a receita operacional bruta é revertida para as comunidades menos favorecidas. São também desenvolvidas ações de ordem educacional relativas ao meio ambiente, por meio de palestras destinada a estudantes da rede pública e privada. Informações do site Scienceme - Usina de Valorização de Recicláveis (UVR) e o Museu do Lixo. Disponível em: https://www.scienceme.com.br/uvrmuseudolixo. Acesso em: 18 out. 2017.

v Informações do site Ecobooking Caminhada da Lua Cheia. Disponível em: http://www.ecobooking.com.br/site3/ destinoEventoSimples.php?Xeven $=$ g1b1wxb15vdemsbm5rr5 Acesso em: 28 set. 2017

vi Informação do site Moto Off Road - Trilheiros tem encontro marcado em outubro na grande Curitiba (PR) - Disponível em: http://www.motooffroad.com.br/noticias/141-trilhao/1032-trilheiros-tem-encontro-marcado-em-outubro-na-grande-curitiba-pr Acesso em: 23 out. 2017.

vii A Rota do Pinhão foi idealizada em 2003 a partir de um trabalho conjunto do Sebrae/PR, Secretaria de Estado do Turismo e Fórum Metropolitano de Turismo com intuito de integrar em rede as empresas de turismo na Região Metropolitana de Curitiba transformando a região em um destino turístico fortalecido (PRTUR; Sebrae, 2014).

viii A Casa do Agricultor se destina a venda de produtos locais - alimentícios e artesanatos - e se encontra na comunidade de Conceição dos Correias.

ix Informações do site da PMCM - Prefeitura Municipal de Campo Magro - Campo Magro Recicla. Disponível em: http:// www.campomagro.pr.gov.br/meio-ambiente/ Acesso em: 14 de jul de 2017.

x PMCM - Prefeitura Municipal de Campo Magro - Turismo Rural. Disponível em: http://www.campomagro.pr.gov.br/meio-ambiente/ Acesso em: 14 de jul de 2017. 